\title{
Electromagnetic Radiation Exposure from Nearby Cellular Base Stations in the Gaza Strip, Palestine: A Concern for Public Health
}

\author{
Samir Yassin', Mohammed Musleh², Samer Abuzerr ${ }^{3,4 *}$ \\ ${ }^{1}$ Department of Physics, Faculty of Sciences, Islamic University of Gaza, Gaza, Palestine \\ ${ }^{2}$ Environmental Quality Authority, Gaza, Palestine \\ ${ }^{3}$ Department of Environmental Health Engineering, Faculty of Public Health, International Campus, Tehran University of \\ Medical Sciences, Tehran, Iran \\ ${ }^{4}$ Quality Improvement and Infection Control Unit, Ministry of Health, Gaza, Palestine \\ Email: ^samer_516@hotmail.com, syassin@iugaza.edu.ps, musleh-enviro@hotmail.com
}

How to cite this paper: Yassin, S., Musleh, M. and Abuzerr, S. (2019) Electromagnetic Radiation Exposure from Nearby Cellular Base Stations in the Gaza Strip, Palestine: A Concern for Public Health. Journal of Biosciences and Medicines, 7, 46-59. https://doi.org/10.4236/jbm.2019.74006

Received: March 7, 2019

Accepted: April 12, 2019

Published: April 15, 2019

Copyright $\odot 2019$ by author(s) and Scientific Research Publishing Inc. This work is licensed under the Creative Commons Attribution International License (CC BY 4.0). http://creativecommons.org/licenses/by/4.0/

\section{Open Access}

\begin{abstract}
The widespread mobile station's antennas and the continued increase in the number of mobile phones users throughout the Gaza strip causing great panic in the population relating the debate overexposure to electromagnetic radiation EMR emitted from the antennas of mobile base stations. Therefore, this study was conducted to measure the levels of electromagnetic radiation emitted from the antennas of cellular base stations in Gaza governorate as well as to evaluate the citizen's awareness and practices regarding potential health risks and mitigation methods of exposure to electromagnetic radiation emitted from cellular base stations, respectively. Fifty cellular base stations out of 197 stations were selected depending on the criteria of selecting one site per kilometer using Global Positioning System (GPS). Electromagnetic power density, electric field strength, and the magnetic field strength emitted from cellular base stations were measured using Narda-550. Assessment tool for observation was used to collect operational information of each station. A structured questionnaire with four-level Likert rating scale was used to survey 384 mobile phone users from the areas surrounding the selected cellular base stations. The results showed that the electromagnetic radiation levels of all stations were low and less than the national and international acceptable limits. Furthermore, the awareness of participant about health risks that could result from exposure to electromagnetic radiation emitted from cellular base stations and mobile phones was low. Nevertheless, the participant's practices in mitigating the adverse impacts of electromagnetic radiation emitted from cellular base stations and mobile phones on their health
\end{abstract}


were good.

\section{Keywords}

Antennas, Cellular Base Stations, Exposure, Electromagnetic Radiation, Gaza Strip, Public Health, Power Density

\section{Introduction}

Mobile or cellular phones are now an integral part of modern telecommunications. In many countries, over half of the population use mobile phones and the market is growing rapidly. In 2014, there were an estimated 6.9 billion subscriptions globally. In some parts of the world, mobile phones are the most reliable or the only phones available [1] [2] [3]. This wireless technology relies upon an extensive network of fixed antennas, or base stations, relaying information with radiofrequency (RF) signals. Over 1.4 million base stations exist worldwide and the number is increasing [4]. The radio waves used in mobile telephone are, like visible light and $\mathrm{X}$-rays, electromagnetic waves that consist of both an electric and a magnetic component which vary periodically in time. The frequency of variation determines the wave properties and uses [5]. Radio waves can be used for various types of communication, are found in the lower part of the spectrum and classified as non-ionizing radiation. There are different types of electromagnetic waves with different frequencies; each has its own properties and characteristics which make it distinguished from others. The electromagnetic radiation may be classified as ionizing and non-ionizing radiation. Ionizing radiation, such as X-rays, has enough energy to remove bound electrons from the orbit of an atom in such a way that it becomes an ionized atom, which may induce health hazard. On the other hand, the non-ionizing radiation, such as visible light, has less energy than ionizing radiation; it does not have sufficient energy to ionize the atoms [6] [7]. A cellular communication system consists of several transmitters called base stations, covering adjoining zones called cells, and the in-use mobile phones. Worldwide, several mobile radio systems are available, ranging from analog to digital systems and having different multiple access types and frequency carriers [8] [9].

Mobile phone companies in Palestine use the global system for mobile communication (GSM) which is a digital mobile telephone system used in most parts of the world. GSM uses a time division multiple access which enables more people to communicate simultaneously with a station [10]. GSM system operates in either the $900 \mathrm{MHz}$ or $1800 \mathrm{MHz}$ band. The $900 \mathrm{MHz}$ band is utilized in Palestine, only 24 channels are allocated for Jawwal Company. According to the Palestinian protocol, the acceptable level for the general public exposure to EMR in term of power density, at a frequency of $900 \mathrm{MHz}$, is $4.0 \mathrm{~W} / \mathrm{m}^{2}$ and $22.5 \mathrm{~W} / \mathrm{m}^{2}$ for occupational exposure [11]. The same levels are also recommended by the world health organization (WHO) [12], and an independent International 
Commission for Non-Ionizing Radiation Protection (ICNIRP) [13].

The tremendous growth in the use of mobile phones has resulted in an increasing number of GSM base stations being built in densely populated areas. Daily exposure to electromagnetic fields has raised the public concern of possible adverse health effects to people living in the vicinity of base station antennas. Radiofrequency and microwave radiation exposures from the antennas of rooftop mounted mobile telephone base stations have become a serious concern in recent years due to the rapidly evolving technologies in wireless telecommunication systems [8].

According to reports from the Palestinian Environmental Quality Authority (EQA), more than 500 mobile phone base station is spread over the Gaza strip and to the best of our knowledge, there are no clear sufficient studies concerning radiation levels measurement and possible health risks. In response to public concerns by the EQA in Palestine, this research is initiated and recommended to assess the electromagnetic radiation levels emitted from mobile phones base stations in Gaza governorate.

\section{Materials and Methods}

\subsection{Study Setting}

The study was conducted in the Gaza governorate, the most densely populated area all over the world. The Gaza governorate $\left(74 \mathrm{~km}^{2}\right)$, the largest in the Gaza strip $\left(365 \mathrm{~km}^{2}\right)$ with a population of 673,638 and population growth rate of $2.92 \%$, is made up of 12 neighborhoods namely: Sheikh Ejleen, Southern Remal, Northern Remal, Al-Daraj, Al-Sabra, Al-Zaytoon, Al-Nasser, Tal Al-Hawa, Al-Shatea camp, Al-Sheikh Radwan, Al-Tuffah, and Al-Shujaeya [14].

\subsection{Data Collection and Sampling Methods}

This study was carried out from $1^{\text {st }}$ of September 2017 to $28^{\text {th }}$ July 2018 by five well-trained engineers and interviewers. Fifty cellular base stations out of 197 stations placed on the Gaza governorate building's rooftops were selected adopting the criteria of selecting one site per kilometer using Global Positioning System (GPS) (Figure 1).

\subsection{Study Tools}

\subsubsection{Assessment Tool for Observation}

Field visits were executed to collect information about the stations using observation tools comprised of five parts; First, general information about the station such as (station name, station location, the suitability of the surrounding area, number of cells, building type, and establishment date). Second, information concerning the height of the station's building and antennas height from the building roof. Third, information regarding the distances between the antenna and both of the protective fence and the nearest neighbor. Fourth, information about the antenna's electromagnetic power density, magnetic field strength, and 


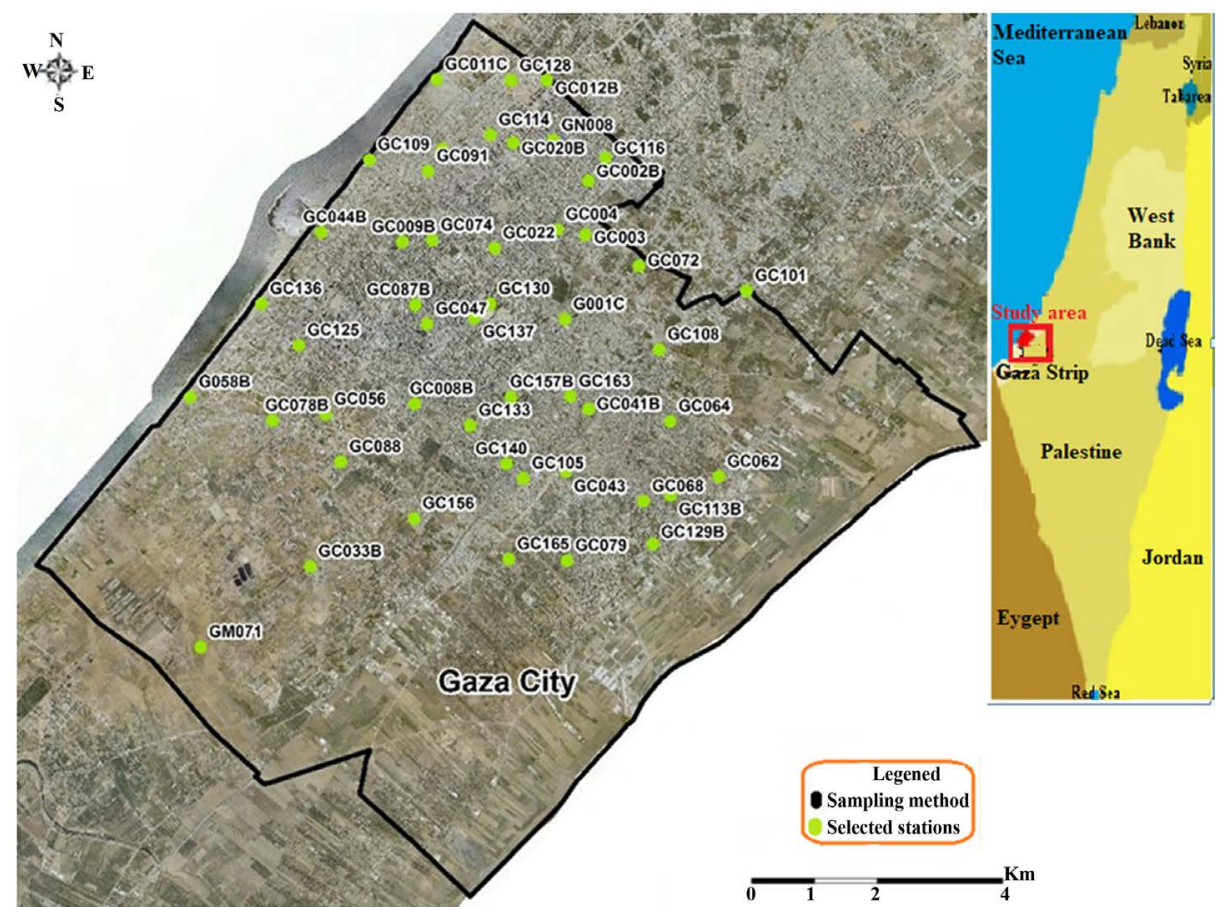

Figure 1. Sampling method relying on selecting one site per kilometer and the fifty selected cellular base stations locations.

electric field strength. Fifth, information about station a license, availability of protective fence, and presence of warning signs.

\subsubsection{Electromagnetic Radiation Measurements}

The EMR emitted from mobile phones base stations was measured on 3, 6, and 20 meters away from station antenna using an NBM-Broadband Field Meter called Narda-550. The electromagnetic power density (S) (Milliwatts per square meter $\mathrm{mW} / \mathrm{cm}^{2}$ ), the electric field strength (E) (Volt per meter $\mathrm{V} / \mathrm{m}$ ), and the magnetic field strength $(\mathrm{H})$ (Ampere per meter $\mathrm{A} / \mathrm{m}$ ) emitted from cellular base stations were measured on 3, 6, and 20 meters away from station antenna and on 3, 6, and 20 meters from the base of the antenna (Figure 2) [15].

The EMR levels outcome were compared with the exposure limits recommended by ICNIRP, WHO, and the Institute of Electrical and Electronics Engineers (IEEE), as well as the environmental quality authority, recommended limits for an environmental protocol for mobile macrocell installation in Palestine, Egypt, and Iraq.

\subsubsection{Structured Questionnaire}

A structured questionnaire developed according to related previous studies [16] [17] [18], was employed in this study to collect data from mobile phone users in the Gaza governorate regarding awareness about health risks that could result from exposure to electromagnetic radiation emitted from cellular base stations (11 items) and their practices in mitigating the adverse impacts of electromagnetic radiation emitted from cellular base stations on their health (13 items). 

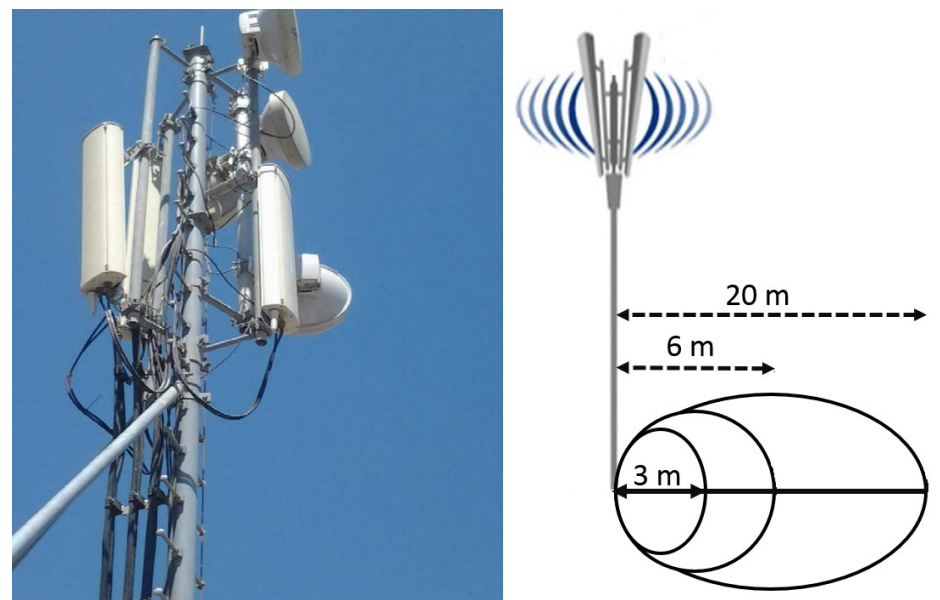

Figure 2. Most commonly used base stations in Gaza city and measurement points in the area surrounding the antenna of cellular base stations.

A four-level Likert rating scale was used to scaling study participants responses as follows:

\begin{tabular}{cc}
\hline Very aware/very good practice (4) & $3.50-4.49$ \\
Aware/good practice (3) & $2.50-3.49$ \\
Fairly aware/fairly good practice (2) & $1.50-2.49$ \\
Unaware/Bad practice (1) & $0.50-1.49$ \\
\hline
\end{tabular}

\subsection{Sample Size Calculation}

Twenty mobile phone users from the area surrounding each cellular base stations were surveyed since the sample size of this study was calculated using Epi Info with a confidence interval of $95 \%$, margin of error of $5 \%$, and response distribution is $50 \%$. The study population composed of 450,000 mobile phone users in the Gaza Governorate. The calculated sample size was 384 mobile phone users.

\subsection{Statistical Analysis and Data Interpretation}

The collected data was analyzed using Microsoft Excel Program and Statistical Package for the Social Sciences (SPSS). The measured electromagnetic power density (S), electric field strength (E), and magnetic field strength $(\mathrm{H})$ values were presented as a minimum, maximum, mean, and standard deviation. The correlation coefficient between the height of the antenna and the electromagnetic power density $(S)$ was identified $(\mathrm{p}<0.05)$. The collected data using the questionnaire were analyzed and presented as a mean and standard deviation. The mean ratings of participants were interpreted using the real limits of numbers to determine the awareness and practice level for each item.

\subsection{Ethical Consideration}

The study protocol was approved by the Palestinian Environmental Quality Au- 
thority. As well, written informed consent was also obtained from each participant.

\section{Results}

\subsection{Characteristics of Cellular Base Stations}

The observational results exhibited that 49 out of 50 stations had three cells. Twenty sex stations located on the roofs of residential towers, 20 stations were on houses rooftops, and 4 stations were established on roofs of institutional buildings. The height of stations cells from the surface of the earth was ranged between 15 to 50 meters for 48 stations whereas it was higher than 50 meters for two stations. The antennas cells (A, B, and $\mathrm{C}$ ) height from the building rooftop were 6 meters higher for all stations. The distance between the antennas bases and protective fences was less than 5 meters for 6 stations, while it was more than 5 meters for 44 stations. The distance between the antenna and the nearest adjacent building was more than 5 meters for the vast majority stations. The antenna's height was higher than 2 meters from the nearest adjacent building located within 10 meters radius for all stations. All stations were licensed by the Palestinian environmental quality authority according to the environmental protocol for mobile macrocell installation. It was noticed that the roofs gates of 13 stations were not completely locked. There was no warning signs and labels in all stations. No antenna's cells directed toward schools.

\subsection{Electromagnetic Power Density (S), Electric Field Strength (E), and Magnetic Field Strength $(\mathrm{H})$ Measurements}

The measured levels of electromagnetic power density (S), electric field strength (E), and magnetic field strength $(\mathrm{H})$ emitted from cellular base stations at 3, 6, and 20 meters are summarized in Tables $1-3$, respectively. In all fifty stations, the results showed that the values of $\mathrm{S}, \mathrm{E}$, and $\mathrm{H}$ vary between the $\mathrm{A}, \mathrm{B}$, and $\mathrm{C}$ cells at different distances of 3,6, and 20 meters. Overall, as shown in Table 1, at

Table 1. Electromagnetic power density (S), electric field strength (E), and magnetic field strength $(\mathrm{H})$ for $\mathrm{A}, \mathrm{B}$, and $\mathrm{C}$ cells of stations at 3 meters.

\begin{tabular}{cccccc}
\hline Variables & Cell & Minimum & Maximum & Mean & Std. Dev. \\
\hline & A & 0 & 0.879 & 0.0064 & 0.0134 \\
S at 3 m (mW/cm $\left.{ }^{2}\right)$ & B & 0.0001 & 0.0864 & 0.00471 & 0.01247 \\
& C & 0 & 0.027 & 0.00335 & 0.00141 \\
& A & 0.60 & 7.51 & 3.3 & 1.65 \\
E at 3 m (V/m) & B & 0.74 & 9.5 & 2.96 & 1.69 \\
& C & 0.3118 & 6.85 & 3.02 & 1.45 \\
& A & 11 & 19.9 & 8.6 & 4.7 \\
H at 3 m $(\mathrm{mA} / \mathrm{m})$ & B & 3.9 & 28.9 & 8.1 & 5.5 \\
& C & 0 & 14.4 & 7.6 & 3.1 \\
\hline
\end{tabular}


Table 2. Electromagnetic power density (S), electric field strength (E), and magnetic field strength $(\mathrm{H})$ for $\mathrm{A}, \mathrm{B}$, and $\mathrm{C}$ cells of stations at 6 meters.

\begin{tabular}{cccccc}
\hline Variables & Cell & Minimum & Maximum & Mean & Std. Dev. \\
\hline & A & 0 & 0.0443 & 0.0034 & 0.0687 \\
S at 6 m (mW/cm $\left.{ }^{2}\right)$ & B & 0 & 0.0147 & 0.00196 & 0.00252 \\
& C & 0 & 0.0385 & 0.00262 & 0.00556 \\
& A & 0.27 & 7.70 & 2.45 & 1.58 \\
E at 6 m (V/m) & B & 0.42 & 7.45 & 2.37 & 1.44 \\
& C & 0.22 & 5.57 & 2.36 & 1.23 \\
& A & 0.3 & 20.4 & 6.7 & 4.76 \\
& B at 6 $\mathrm{m}(\mathrm{mA} / \mathrm{m})$ & 0.4 & 19.8 & 6.2 & 6.2 \\
& C & 0.6 & 14.8 & 6.3 & 3.2 \\
\hline
\end{tabular}

Table 3. Electromagnetic power density (S), electric field strength (E), and magnetic field strength $(\mathrm{H})$ for $\mathrm{A}, \mathrm{B}$, and $\mathrm{C}$ cells of stations at 20 meters.

\begin{tabular}{cccccc}
\hline Variables & Cell & Minimum & Maximum & Mean & Std. Dev. \\
\hline S at $20 \mathrm{~m}\left(\mathrm{~mW} / \mathrm{cm}^{2}\right)$ & B & 0 & 0.0007 & 0.00014 & 0.00018 \\
& C & 0 & 0.0008 & 0.00014 & 0.00017 \\
& A & 0.04 & 1.65 & 0.56 & 0.0013 \\
E at $20 \mathrm{~m}(\mathrm{~V} / \mathrm{m})$ & B & 0.09 & 1.8 & 0.00183 & 0.6 \\
& C & 0.08 & 2.68 & 0.77 & 0.38 \\
& A & 1 & 9 & 1.6 & 0.53 \\
$\mathrm{H}$ at $20 \mathrm{~m}(\mathrm{~mA} / \mathrm{m})$ & B & 0.1 & 7.5 & 1.7 & 1.4 \\
& C & 0.1 & 7.1 & 2 & 1.4 \\
\hline
\end{tabular}

3 meters, the mean values of $\mathrm{S}$ measurements were $64.64 \times 10^{-4} \mathrm{~mW} / \mathrm{cm}^{2}, 47.1 \times$ $10^{-4} \mathrm{~mW} / \mathrm{cm}^{2}$, and $33.5 \times 10^{-4} \mathrm{~mW} / \mathrm{cm}^{2}$ for the cells of $\mathrm{A}, \mathrm{B}$, and $\mathrm{C}$, respectively. Moreover, the mean values of $E$ measurements were $3.3 \mathrm{~V} / \mathrm{m}, 2.69 \mathrm{~V} / \mathrm{m}$, and $3.02 \mathrm{~V} / \mathrm{m}$ for the cells of $\mathrm{A}, \mathrm{B}$, and $\mathrm{C}$, respectively. Moreover, the mean values of E measurements were $8.6 \mathrm{~mA} / \mathrm{m}, 8.1 \mathrm{~mA} / \mathrm{m}$, and $7.6 \mathrm{~mA} / \mathrm{m}$ for the cells of $\mathrm{A}, \mathrm{B}$, and $\mathrm{C}$, respectively.

Table 2 depicts variations in the $\mathrm{S}, \mathrm{E}$, and $\mathrm{H}$ values among the antennas $\mathrm{A}, \mathrm{B}$ and $C$ cells at 6 meters. The mean values of $S$ measurements were $34 \times 10^{-4}$ $\mathrm{mW} / \mathrm{cm}^{2}, 19.6 \times 10^{-4} \mathrm{~mW} / \mathrm{cm}^{2}$, and $26.2 \times 10^{-4} \mathrm{~mW} / \mathrm{cm}^{2}$ for the cells of $\mathrm{A}, \mathrm{B}$, and $\mathrm{C}$, respectively. The mean values of $\mathrm{E}$ measurements were $2.45 \mathrm{~V} / \mathrm{m}, 2.37$ $\mathrm{V} / \mathrm{m}$, and $2.36 \mathrm{~V} / \mathrm{m}$ for the cells of $\mathrm{A}, \mathrm{B}$, and $\mathrm{C}$, respectively. In addition, the mean values of $E$ measurements were $6.7 \mathrm{~mA} / \mathrm{m}, 6.2 \mathrm{~mA} / \mathrm{m}$, and $6.3 \mathrm{~mA} / \mathrm{m}$ for the cells of A, B, and C, respectively.

Table 3 presents a summary of the $\mathrm{S}, \mathrm{E}$, and $\mathrm{H}$ measurements at 20 meters. The mean values of $\mathrm{S}$ measurements were $1.4 \times 10^{-4} \mathrm{~mW} / \mathrm{cm}^{2}, 1.4 \times 10^{-4} \mathrm{~mW} / \mathrm{cm}^{2}$, 
and $1.83 \times 10^{-4} \mathrm{~mW} / \mathrm{cm}^{2}$ for the cells of $\mathrm{A}, \mathrm{B}$, and $\mathrm{C}$, respectively. The mean values of $\mathrm{E}$ measurements were $0.56 \mathrm{~V} / \mathrm{m}, 0.6 \mathrm{~V} / \mathrm{m}$, and $0.77 \mathrm{~V} / \mathrm{m}$ for the cells of $\mathrm{A}$, $\mathrm{B}$, and $\mathrm{C}$, respectively. The mean values of $\mathrm{E}$ measurements were $1.6 \mathrm{~mA} / \mathrm{m}, 1.7$ $\mathrm{mA} / \mathrm{m}$, and $2 \mathrm{~mA} / \mathrm{m}$ for the cells of $\mathrm{A}, \mathrm{B}$, and C, respectively.

\subsection{The Correlation Coefficient between the Height of the Antenna and the Electromagnetic Power Density (S)}

There is no association between the electromagnetic power density and the antennas heights at different distances since $p$-values for all cells and at all distances were greater than 0.05 (Table 4).

\subsection{Sociodemographic Characteristics of the Study Participants}

A total of 384 mobile phone users were interviewed, the vast majority of them (85.1\%) were males. About $48.2 \%$ of the respondents were university-educated people. The mean age of the study participant was 39 years old.

\subsection{Citizen's Awareness of Health Risks That Could Result from Exposure to Electromagnetic Radiation Emitted from Cellular Base Stations}

Table 5 revealed that the overall mean of participant's awareness about health

Table 4. A correlation coefficient between the height of the antenna and the electromagnetic power density (S).

\begin{tabular}{|c|c|c|c|c|c|}
\hline & & & Height at $3 \mathrm{~m}$ & Height at $6 \mathrm{~m}$ & Height at $20 \mathrm{~m}$ \\
\hline \multirow{6}{*}{ Cell A } & \multirow{2}{*}{$\mathrm{S}$ at $3 \mathrm{~m}$} & Correlation coefficient & 0.22 & & \\
\hline & & Sig. (2-Tailed) & 0.13 & & \\
\hline & \multirow{2}{*}{$\mathrm{S}$ at $6 \mathrm{~m}$} & Correlation coefficient & & 0.20 & \\
\hline & & Sig. (2-Tailed) & & 0.16 & \\
\hline & \multirow{2}{*}{$\mathrm{S}$ at $20 \mathrm{~m}$} & Correlation coefficient & & & 0.08 \\
\hline & & Sig. (2-Tailed) & & & 0.59 \\
\hline \multirow{6}{*}{ Cell B } & \multirow{2}{*}{$\mathrm{S}$ at $3 \mathrm{~m}$} & Correlation coefficient & -0.14 & & \\
\hline & & Sig. (2-Tailed) & 0.32 & & \\
\hline & \multirow{2}{*}{$\mathrm{S}$ at $6 \mathrm{~m}$} & Correlation coefficient & & -0.12 & \\
\hline & & Sig. (2-Tailed) & & 0.42 & \\
\hline & \multirow{2}{*}{$\mathrm{S}$ at $20 \mathrm{~m}$} & Correlation coefficient & & & 0.19 \\
\hline & & Sig. (2-Tailed) & & & 0.19 \\
\hline \multirow{6}{*}{ Cell C } & \multirow{2}{*}{$\mathrm{S}$ at $3 \mathrm{~m}$} & Correlation coefficient & -0.03 & & \\
\hline & & Sig. (2-Tailed) & 0.98 & & \\
\hline & \multirow{2}{*}{$\mathrm{S}$ at $6 \mathrm{~m}$} & Correlation coefficient & & -0.06 & \\
\hline & & Sig. (2-Tailed) & & 0.97 & \\
\hline & \multirow{2}{*}{$\mathrm{S}$ at $20 \mathrm{~m}$} & Correlation coefficient & & & 0.25 \\
\hline & & Sig. (2-Tailed) & & & 0.08 \\
\hline
\end{tabular}


Table 5. Participant's awareness of health risks that could result from exposure to electromagnetic radiation emitted from cellular base stations.

\begin{tabular}{|c|c|c|c|}
\hline Items & Mean & $\begin{array}{l}\text { Standard } \\
\text { Deviation }\end{array}$ & Comment \\
\hline $\begin{array}{l}\text { 1) Long exposure to electromagnetic radiation emitted from a } \\
\text { mobile phone may cause cancer }\end{array}$ & 3.71 & 0.52 & Very Aware \\
\hline $\begin{array}{l}\text { 2) Long exposure to electromagnetic radiation emitted from a } \\
\text { mobile phone may cause tiredness }\end{array}$ & 1.44 & 0.56 & Unaware \\
\hline $\begin{array}{l}\text { 3) Long exposure to electromagnetic radiation emitted from a } \\
\text { mobile phone may cause diarrhea }\end{array}$ & 1.36 & 0.91 & Unaware \\
\hline $\begin{array}{l}\text { 4) Long exposure to electromagnetic radiation emitted from a } \\
\text { mobile phone may cause cardiac problems }\end{array}$ & 2.21 & 0.68 & Fairly aware \\
\hline $\begin{array}{l}\text { 5) Long exposure to electromagnetic radiation emitted from a } \\
\text { mobile phone may cause memory impairment }\end{array}$ & 1.2 & 0.69 & Unaware \\
\hline $\begin{array}{l}\text { 6) Long exposure to electromagnetic radiation emitted from a } \\
\text { mobile phone may cause a headache }\end{array}$ & 1.43 & 0.83 & Unaware \\
\hline $\begin{array}{l}\text { 7) Long exposure to electromagnetic radiation emitted from a } \\
\text { mobile phone may cause dizziness }\end{array}$ & 1.33 & 0.56 & Unaware \\
\hline $\begin{array}{l}\text { 8) Long exposure to electromagnetic radiation emitted from a } \\
\text { mobile phone may cause sleep disturbance }\end{array}$ & 1.67 & 0.77 & Fairly aware \\
\hline $\begin{array}{l}\text { 9) Long exposure to electromagnetic radiation emitted from a } \\
\text { mobile phone may cause depression and anxiety }\end{array}$ & 1.68 & 0.69 & Fairly aware \\
\hline $\begin{array}{l}\text { 10) Long exposure to electromagnetic radiation emitted from a } \\
\text { mobile phone may cause infertility }\end{array}$ & 2.66 & 0.68 & Aware \\
\hline $\begin{array}{l}\text { 11) Long exposure to electromagnetic radiation emitted from a } \\
\text { mobile phone may cause perception impairment }\end{array}$ & 1.42 & 0.6 & Unaware \\
\hline
\end{tabular}

risks that could result from exposure to electromagnetic radiation emitted from cellular base stations was 1.83 , indicating a low level of awareness about health risks induced by the exposure to electromagnetic radiation emitted from cellular base stations. Moreover, the standard deviation of the participant's responses ranged between 0.52 and 0.91 , demonstrating the participant's responses tend to be close to the mean of the set. The study participants were very aware concerning long exposure to electromagnetic radiation emitted from a mobile phone may cause cancer. In addition, they were aware of long exposure to electromagnetic radiation emitted from a mobile phone may lead to infertility. Fairly awareness of that long exposure to electromagnetic radiation emitted from a mobile phone may cause cardiac problems, sleep disturbance, and depression and anxiety were obtained. However, they were unaware that long exposure to electromagnetic radiation emitted from a mobile phone may cause tiredness, diarrhea, memory impairment, headache, dizziness, and perception impairment.

\subsection{Citizen's Practices in Mitigating the Adverse Impacts of Electromagnetic Radiation Emitted from Cellular Base Stations on Their Health}

Table 6 revealed that the overall mean of the participant's practices in mitigating the adverse impacts of electromagnetic radiation emitted from cellular base stations 
Table 6. Participant's practices in mitigating the adverse impacts of electromagnetic radiation emitted from cellular base stations on their health.

\begin{tabular}{|c|c|c|c|}
\hline Items & Mean & $\begin{array}{l}\text { Standard } \\
\text { Deviation }\end{array}$ & Comment \\
\hline $\begin{array}{l}\text { 1) Using Air Tube earpiece/Bluetooth earpiece or the speaker } \\
\text { function, When using the mobile phone }\end{array}$ & 3.12 & 0.49 & Good practice \\
\hline $\begin{array}{l}\text { 2) Turning off WIFI and } 3 G / 4 G \text { Data connection on your } \\
\text { smartphone when not in use }\end{array}$ & 2.21 & 0.62 & Fairly good practice \\
\hline $\begin{array}{l}\text { 3) Unplugging the mobile phone from the power, when not } \\
\text { in use }\end{array}$ & 3.51 & 0.64 & Very good practice \\
\hline 4) Avoid staying long in place in which there is a lot of EMR & 3.08 & 0.62 & Good practice \\
\hline 5) Putting the mobile away from the body & 2.66 & 0.36 & Good practice \\
\hline 6) Using a holster designed to shield the body from radiation & 3.13 & 0.41 & Good practice \\
\hline $\begin{array}{l}\text { 7) Avoid using a mobile phone in a moving car, train, bus, or } \\
\text { in rural areas at some distance from a cell tower }\end{array}$ & 1.6 & 0.5 & Fairly good practice \\
\hline $\begin{array}{l}\text { 8) Avoid sleeping when cell phone beneath the pillow or } \\
\text { close to the bedside }\end{array}$ & 3.77 & 0.71 & Very good practice \\
\hline 9) Switching off the mobile phone when not in use & 3.13 & 0.48 & Good practice \\
\hline $\begin{array}{l}\text { 10) Staying away from people who heavily use mobile } \\
\text { phones }\end{array}$ & 3.1 & 0.62 & Good practice \\
\hline 11) Avoid carrying mobile phones in shirts pockets or in bras & 2.81 & 0.62 & Good practice \\
\hline 12) Always using a landline telephone & 1.2 & 0.44 & Bad practice \\
\hline 13) Avoiding unjustified use of the mobile phone & 2.39 & 0.62 & Fairly good practice \\
\hline
\end{tabular}

on their health was 2.75 , showing a good level of their practices in mitigating the adverse impacts of electromagnetic radiation emitted from cellular base stations on their health. Moreover, the standard deviation of the participant's responses ranged between 0.36 and 0.71 , proving the participant's responses tend to be close to the mean of the set.

The study participants had a very good practice regarding unplugging the mobile phone from the power, when not in use and avoid sleeping when cell phone beneath the pillow or close to the bedside. However, they had a bad practice of avoiding using a landline telephone.

\section{Discussion}

The Palestinian mobile macro-cell installation protocol has been recently issued in collaboration between the Palestinian environment quality authority, ministry of health, and ministry of telecommunications. The protocol items were computable with the international standards in the installation of cellular base stations [13]. Based on our study findings, most protocol items were achieved. The protocol states that the height of building the antenna install above must be between 15 - 50 meters from the ground surface. In case of this length is not achieved in the building, antennas have to be installed on a metal tower or mast to make up the shortfall in height. The height of the antenna from the nearest 
building located within 10 meters radius is not less than 2 meters. The roof of the building must be of reinforced concrete. Antennas height from the building roof must not be less than 6 meters. The distance between two stations at the same building roof must not be less than 12 meters. The distance between the antenna and the protective fence must not be less than 5 meters. In our study, the maximum measured electromagnetic power density, electric field strength, and magnetic field strength were $0.879 \mathrm{~mW} / \mathrm{cm}^{2}, 9.5 \mathrm{~V} / \mathrm{m}$, and $28.9 \mathrm{~mA} / \mathrm{m}$ at 3 meters from the antenna, respectively which were less than national and international permissible limits [3] [11] [13] [19] [20] [21].

The study conducted in 2005 to measure and theoretically estimation of electromagnetic fields from mobile telephones and their base stations in the Gaza governorate stated that real measurements were inconsistent with theoretical ones and they are much lower than the exposure limit recommended by the international limits [5]. In addition, the study conducted in Nablus governorate in the westbank, Palestine by Mousa, 2011 [22] to measure the electromagnetic radiation emitted from cellular base stations revealed that the exposure levels from that stations met the ICNIRP and FCC standards. Also, comparable results were found by Nayyeri et al., 2012 [23] where the radiofrequency radiation levels measured in 900 locations around 60 mobile phone base stations in Tehran were within the permissible limits of the ICNIRP. A similar study was carried out in Al-Khartoum city in Sudan reported that the maximum value of power density was $0.025 \mathrm{~W} / \mathrm{m}^{2}$ which is quite small compared to the ICNIRP limits of 4.5 $\mathrm{W} / \mathrm{m}^{2}$ for the public and $22.5 \mathrm{~W} / \mathrm{m}^{2}$ for the telecommunications workers [24].

A number of investigations have recognized health-related indications due to the extensive use of mobile phones and living in neighborhoods near the cellular base stations [17] [25] [26] [27] [29]. Nonetheless, other researchers have stated inconsistent outcomes concerning the possible consequences of electromagnetic fields emitted from cellular base stations and mobile phones on human health [29] [30]. Fatigue, headache, diarrhea, sleep disruption, dizziness, and loss of memory symptoms were self-reported symptoms by an individual's residence within $300 \mathrm{~m}$ of cellular base stations in France [31]. Similarly, the above-mentioned symptoms were noticed as harmful effects related to mobile phones university students in a Malaysian medical school [32]. However, further investigations are required to prove the recent debate of increase cancers incidence among exposed people to low-level exposure to radiofrequency electromagnetic fields from cellular base stations [3] [33]. Comparable results were found by Owodunni Ayanda Samuel et al., 2017 [17] where a low level of awareness of the of electromagnetic waves radiated by the phones among the population of Bosso, Niger State, Nigeria.

\section{Conclusions and Recommendations}

The electromagnetic power density, electric field strength, and the magnetic field strength emitted from cellular base stations were measured on 3, 6, and 20 meters away from station antenna and on 3, 6, and 20 meters from the base of the 
antenna were low and less than the Palestinian protocol and international acceptable limits. No relationship between the electromagnetic power density and the antenna heights at different distances was found. The heights of the station from the earth's surface almost ranged between 15 and 50 meters. The distance between the antenna and the protective fence was more than 5 meters and the height of antenna from the nearest building found within 10 meters radius was higher than 2 meters for all stations for the majority of stations. All stations were licensed by the EQA; however, it was noticed that the roof's gates of 13 stations were not completely locked. There were no warning signs and labels in all stations. No antenna's cells directed toward schools. Furthermore, the awareness of participants about health risks that could result from exposure to electromagnetic radiation emitted from cellular base stations and mobile phones was low. Nevertheless, the participant's practices in mitigating the adverse impacts of electromagnetic radiation emitted by cellular base stations and mobile phones on their health were good practices.

Consistent with the study outcomes, we offer the following recommendations:

1) The telecommunication companies commitment to providing the required warning signs in the area of Cellular Base Stations according to the environmental protocol for mobile macrocell installation in Palestine.

2) Regular monitoring and periodic surveillance should be carried out by the Palestinian EQA and other stakeholders to ensure the operations performance of base stations and to guarantee that public persons cannot access the base station.

3) Sensitization awareness-raising campaigns to improve public consciousness concerning health risks that could result from exposure to electromagnetic radiation emitted from cellular base stations as well.

4) Efforts should be made by the community institution to promote best practices in mitigating the adverse impacts of electromagnetic radiation emitted from cellular base stations on their health.

5) Our study call for epidemiological future studies to investigate the association between exposures to RF emitted from mobile telephone base stations or broadcasting transmitters and incidence of diseases throughout Gaza strip.

\section{Acknowledgements}

Palestinian Environmental Quality Authority is appreciated for giving us the opportunity to implement this study. The authors would like to thank the participants in this study for their important contributions.

\section{Funding}

This research did not receive any specific grant from funding agencies in the public, commercial or not-for-profit sectors.

\section{Conflicts of Interest}

The authors declare that they have no competing interests. 


\section{References}

[1] Gartner (2011) Gartner Says Mobile Phone Sales Will Exceed One Billion in 2009. Press Release.

[2] Motorola (2006) Towards the Next Billion Subscribers: Motorola Delivers on Seamless Mobility Vision.

[3] WHO (2014) Electromagnetic Fields and Public Health. World Health Organization.

[4] WHO (2012) Base Stations and Wireless Technologies. World Health Organization.

[5] Abdelati, M.M. (2015) Electromagnetic Radiation from Mobile Phone Base Stations at Gaza. IUG Journal for Natural and Engineering Studies, 13.

[6] Ishimaru, A. (2017) Electromagnetic Wave Propagation, Radiation, and Scattering: From Fundamentals to Applications. John Wiley \& Sons, Hoboken.

https://doi.org/10.1002/9781119079699

[7] Wang, W.-C. (1986) Electromagnetic Wave Theory.

[8] Al-Bazzaz, S.H.S. (2008) Theoretical Estimation of Power Density Levels around Mobile Telephone Base Stations. Journal of Science and Technology, 13.

[9] Mousa, A. (2014) Electromagnetic Radiation Measurements and Safety Issues of some Cellular. Journal of Engineering Science and Technology Review, 4, 35-42. https://doi.org/10.25103/jestr.041.05

[10] Biebuma, J. and Esekhaigbe, E. (2016) Assessment of Radiation Hazards from Mobile Phones and GSM Base Stations. Journal of Innovative Research in Engineering and Sciences, 2.

[11] EQA (2008) Environmental Protocol for Mobile Macro Cell Installation, Gaza, Palestine. Environmental Quality Authority.

[12] WHO (2005) Electromagnetic Fields and Public Health: Mobile Telephones and their Base Stations. World Health Organization Fact Sheet No. 31, 1-65.

[13] ICNIRP (1998) Guidelines for Limiting Exposure to Time-Varying Electric, Magnetic and Electromagnetic Fields (up to $300 \mathrm{GHz}$ ). International Commission on Non-Ionizing Radiation Protection Health Physics, 74, 494-522.

[14] PCBS (2018) Localities in Gaza Governorate by Type of Locality and Population Estimates 2007-2016. Palestinian Central Bureau of Statistics.

[15] Narda (2006) Narda Broadband Field Meter (NBM-550), Operating Manual: Narda Safety Test Solutions Company. 1-4, 113-116.

[16] Osmen, W. and Saar, A.A.A. (2015) Awareness Campaign against Cell Phone Radiation Hazard: Case Study Oman. Procedia-Social and Behavioral Sciences, 205, 381-386. https://doi.org/10.1016/j.sbspro.2015.09.017

[17] Samuel, O.A., Emmanuel, R. and Abraham, E.O. (2017) Awareness of the Possible Hazards of Electromagnetic Waves Radiation among Mobile Phone Users in Bosso, Niger State, Nigeria. Engineering and Technology, 4, 65-69.

[18] Shariful Islam, S.M. (2014) Awareness and Self-Reported Health Hazards of Electromagnetic Waves from Mobile Phone towers in Dhaka, Bangladesh: A Pilot Study. Advances in Public Health, 2014, Article ID: 952832. https://doi.org/10.1155/2014/952832

[19] FCC (2011) Radiofrequency Radiation Exposure Limits, Federal Washington.

[20] IEEE (1999) The Standard for Safety Levels with Respect to Human Exposure to Radio Frequency Electromagnetic Fields, 3 kHz to 300 GHz. New York, 6-10. 
[21] Mobinil (2013) Interesting Facts: The Egyptian Company for Mobile Services. https://www.mobinil.com/en/about/company-overview/socialresponsibility/health/i nteresting-facts

[22] Mousa, A. (2011) Electromagnetic Radiation Measurements and Safety Issues of some Cellular Base Stations in Nablus. Journal of Engineering Science \& Technology Review, 4, 35-42. https://doi.org/10.25103/jestr.041.05

[23] Nayyeri, V., Hashemi, S.M., Borna, M., Jalilian, H.-R. and Soleimani, M. (2012) Assessment of RF Radiation Levels in the Vicinity of 60 GSM Mobile Phone Base Stations in Iran. Radiation Protection Dosimetry, 155, 241-244. https://doi.org/10.1093/rpd/ncs319

[24] Ahmad, R.S.A.Q. (2017) Radiation Levels from Microcell Mobile Telephony Base Stations in Bethlehem and Hebron Cities Palestine, AL-Quds University.

[25] Nittby, H., Grafström, G., Tian, D.P., Malmgren, L., Brun, A., Persson, B.R., Salford, L.G. and Eberhardt, J. (2008) Cognitive Impairment in Rats after Long-Term Exposure to GSM-900 Mobile Phone Radiation. Bioelectromagnetics: Journal of the Bioelectromagnetics Society, 29, 219-232. https://doi.org/10.1002/bem.20386

[26] Ozovehe, A., Usman, A. and Hamdallah, A. (2015) Electromagnetic Radiation Exposure from Cellular Base Station: A Concern for Public Health. Nigerian Journal of Technology, 34, 355-358. https://doi.org/10.4314/njt.v34i2.20

[27] SCENIHR (2006) Possible Effects of Electromagnetic Fields (EMF) on Human Health Scientific Committee on Emerging and Newly Identified Health Risks.

[28] Wdowiak, A., Wdowiak, L. and Wiktor, H. (2007) Evaluation of the Effect of Using Mobile Phones on Male Fertility. Annals of Agricultural and Environmental Medicine, 14, 169-172.

[29] Haarala, C., Takio, F., Rintee, T., Laine, M., Koivisto, M., Revonsuo, A. and Hämäläinen, H. (2007) Pulsed and Continuous Wave Mobile Phone Exposure over Left versus Right Hemisphere: Effects on Human Cognitive Function. Bioelectromagnetics: Journal of the Bioelectromagnetics Society, 28, 289-295. https://doi.org/10.1002/bem.20287

[30] Kwon, M.S., Koivisto, M., Laine, M. and Hämäläinen, H. (2008) Perception of the Electromagnetic Field Emitted by a Mobile Phone. Bioelectromagnetics. Journal of the Bioelectromagnetics Society, 29, 154-159. https://doi.org/10.1002/bem.20375

[31] Santini, R., Santini, P., Le Ruz, P., Danze, J. and Seigne, M. (2003) Survey Study of People Living in the Vicinity of Cellular Phone Base Stations. Electromagnetic Biology and Medicine, 22, 41-49. https://doi.org/10.1081/JBC-120020353

[32] Maier, M., Blakemore, C. and Koivisto, M. (2000) The Health Hazards of Mobile Phones: The Only Established Risk Is of Using One While Driving. British Medical Journal, 320, 1288-1289. https://doi.org/10.1136/bmj.320.7245.1288

[33] Repacholi, M.H. (1998) Low-Level Exposure to Radiofrequency Electromagnetic Fields: Health Effects and Research Needs. Bioelectromagnetics. Journal of the Bioelectromagnetics Society, 19, 1-19.

https://doi.org/10.1002/(SICI)1521-186X(1998)19:1<1::AID-BEM1>3.0.CO;2-5 